\title{
Application of Hellison's Teaching Personal and Social Responsibility Model in Physical Education to Improve Self-Efficacy for Adolescents at Risk of Dropping-out of School
}

\author{
Amparo Escartí, Melchor Gutiérrez, Carmina Pascual, and Diana Marín
}

Universitat de València (Spain)

\begin{abstract}
This study evaluated improvement in self-efficacy and personal and social responsibility among at-risk of dropping-out of school adolescents participating in a program in which Hellison's Teaching Personal and Social Responsibility Model was applied in physical education classes during the course of an academic year. Thirty atrisk adolescents aged 13-14 years old ( 23 boys, 7 girls) were assigned to an intervention group (12 boys and 3 girls) or a comparison group (11 boys, 4 girls), the latter of which did not participate in the program. Quantitative results showed a significant improvement in the students' self-efficacy for enlisting social resources and in self-efficacy for self-regulated learning. Qualitative results showed an improvement in responsibility behaviors of participants in the intervention group. This suggests that the model could be effective for improving psychological and social development in at-risk adolescents, and that physical education classes may be an appropriate arena for working with these young people.

Keywords: at-risk adolescents, personal and social responsibility, self-efficacy, physical education.
\end{abstract}

\begin{abstract}
Este estudio evaluó la mejora en autoeficacia y responsabilidad personal y social de un grupo de adolescentes en riesgo de abandono escolar que participaron en un programa basado en el Modelo de Enseñanza de Responsabilidad Personal y Social de Hellison, durante las clases de educación física, a lo largo de un curso académico. La muestra estuvo compuesta por treinta adolescentes de 13 a 14 años de edad (23 chicos, 7 chicas). De ellos, 12 chicos y 3 chicas fueron asignados a un grupo de intervención, y 11 chicos y 4 chicas formaron el grupo de comparación, los cuales no participaron en el programa. Los resultados cuantitativos mostraron una mejora significativa en la autoeficacia de los alumnos para conseguir recursos sociales y en la autoeficacia para el aprendizaje autorregulado. Los análisis cualitativos mostraron que los alumnos del grupo de intervención apreciaron mejoras en su conducta responsable y en la responsabilidad de sus iguales. Esto sugiere que el modelo puede ser efectivo para mejorar el desarrollo psicológico y social de los adolescentes en riesgo, y que las clases de educación física pueden ser un marco apropiado para trabajar con estos jóvenes.
\end{abstract}

Palabras clave: adolescentes en riego, responsabilidad personal y social, autoeficacia, educación física.

This research project has been funded by the Generalitat Valenciana (GV000-025-7) and the Ministerio de Ciencia y Tecnología of the Spanish Government (PGC-2000-2225-E).

Correspondence concerning this article should be addressed to Amparo Escartí. Departamento de Psicología Social. Facultad de Psicología. Universitat de València. Av. Blasco Ibáñez, 21, 46010 Valencia. (España). E-mail: amparo.escarti@uv.es 
Adolescence is a transitional period during which important physical, psychological and social changes take place (Steinberg, 1993). The term "at-risk" is imprecise when applied to adolescents, but a suitable definition within this context is the unlikelihood of acquiring the knowledge, skills, and attitudes needed to become successful adults and, specifically, the exhibition of behavior that makes graduation from high school unlikely (Herr, 1989; Collingwood, 1997).

During the twentieth century, the life experiences of adolescents changed substantially. Nowadays they have more access to drugs and are more exposed to electronic media, which bombards them with messages about fashion, money, fame and violence (Weissberg, Kumpfer, \& Seligman, 2003). Teachers are now having to cope with increasingly more angry, violent adolescents in the classroom; students who lack social and emotional competencies (Weisberg et al., 2003). The perceived need to promote positive youth development in this population has increased over the past 30 years, and a growing number of these programs are based on sport and physical activity (Cecchini, Montero, Alonso, Izquierdo, \& Contreras, 2007; Collingwood, 1996; Danish, Forneris, \& Wallace, 2005; Petitpas, Cornelius, Van Raalte, \& Jones, 2005; Sandford, Armour, \& Warmington, 2006).

Hellison's Teaching Personal and Social Responsibility Model (TPSR) (1985, 1995, \& 2003) emphasizes the need to teach, through sports and physical activity, values and behavior that can contribute to the positive development of students' lives. Hellison's TPSR model identifies two values associated with well-being and personal development: effort and self-management. Two other values are associated with social integration and development: respect for other people's feelings and rights, and caring.

Although some authors consider the TPSR model to be the perfect instrument for designing physical education classes (Siedentop, 1994), most of the TPSR programs are offered in extended-day settings, summer sport camps and alternative schools (Hellison \& Walsh, 2002). Only a few studies have implemented the TPSR model through school based physical education classes, as in the case of Wright and Burton (2008). That study aimed to systematically explore the implementation and short-term outcomes of a responsibility-based physical activity program that was integrated into an intact high school physical education class. Similarly to other studies, this research revealed that the TPSR fostered a positive learning environment and influenced student behavior (Cutforth \& Puckett, 1999; DeBusk \& Hellison, 1989; Escartí, Gutiérrez, Pascual, Marín,Martínez-Taboada, \& Chacón, 2006; Hellison \& Wright, 2003). Hellison and Walsh, (2002) reviewed 26 studies using the TPSR model, and concluded that, though more research was required, there was strong evidence of the theoretical and practical potential of the TPSR as a program for underserved and at-risk youth.
In the present study we implemented the TPSR model during the physical education classes of a group of teenagers at risk of dropping out of school. The objectives were to improve personal and social responsibility and the self-efficacy of the adolescents. A major challenge faced by adolescents is the acquiring of a sense of personal agency and self-efficacy (Zimmerman \& Cleary, 2006). Personal efficacy as a vital personal resource is widely documented as being a determinant in an individual's beliefs about what he or she is or is not capable of accomplishing, and these beliefs in turn have an impact on the interest, effort and persistence that individuals apply to a certain activity (Bandura, 1977, 1997). Self-efficacy refers to "belief in one's capabilities to organize and execute the courses of action required to produce given attainments" (Bandura, 1997, p.3). In social-cognitive theory children who enter adolescence with a robust sense of efficacy for coping with its unique stressors and interpersonal demands are less likely to be vulnerable to stress and disfunction (Bandura, 1997; Caprara, Barbaranelli, Pastorelli, \& Cervone, 2004). Youngsters who have a high sense of personal efficacy in key life domains such as social interactions are more likely to face challenges in a persevering and relatively anxietyfree manner (Bandura, 1997). One's sense of self-efficacy is determined by an array of personal, social, and environmental factors. From the social-cognitive perspective, these factors can be changed not only to influence one's level of selfefficacy, but also subsequent performance on criterial tasks. The personalization of instructional context is predicted to be an effective strategy for raising the learners' percepts of efficacy through the instructional design strategies of enactive experience, vicarious modeling, and persuasory information.

Hellison's Teaching Personal and Social Responsibility Model (TPSR; 1985, 1995, \& 2003) was designed to help youths at-risk to experience success and therefore to promote the development of their personal and social skills and social responsibility in both sports and life in general. In this way, by helping kids redefine success, selfconfidence can be fostered. We hypothesized that applying the TPSR model through physical education classes would be an appropriate medium for teaching personal and social responsibility and for experiencing success. Namely, personal and social self-efficacy of the adolescent participants would improve by acquiring higher levels of both personal and social responsibility and by experiencing success in the activities of the program. For this research, four skill domains were associated with the TPSR model with respect to adolescent participants. These included Enlisting Social Resources (to be able to ask for help when you need it), Self-Regulated Learning (how well can you organize your school work), Self-Regulatory Efficacy (how well you control your temper), and Social Self-Efficacy (how well you communicate effectively with others). 
The longevity of the effect of the program is an important factor to assess. The majority of research analyzes the effects of the program when the intervention ends and very few reports have evaluated the behavior of participants over an extended period of time following the program (Catalano, Berglund, Ryan, Lonczak, \& Hawkins, 1998).

In this study we attempt to answer several questions: (a) What changes do teachers perceive in their students after the program?, (b) What changes in their behavior do adolescents perceive after participating in the program over a school year?, (c) Does the personal and social responsibility model help to improve the personal and social self-efficacy of participants after the program?, and (d) Are physical education classes an opportune environment for teaching reponsibility values and behavior?

\section{Methods}

\section{Participants and Setting}

Participants were composed of two groups of 2 nd year Secondary Education students belonging to a program named "Group Adaptation Program (GAP)". The GAP was directed at 2 nd year secondary students whose low academic achievement is associated with problems of adaptation to work in the classroom and places them at serious risk of dropping out of the educational system. These students were referred into the GAP group by the Department of Counselling Service of the school based on data provided by a team of teachers.

The total number of participants in our study was 30 adolescents ( 23 boys and 7 girls) between 13 and 14 years old $(M=13.20 ; S D=.40)$ from two public secondary schools situated in a locality close to the city of Valencia (Spain). As they were two intact groups, one was randomly designated as the intervention group and the other as the comparison group. The former consisted of 15 adolescents (12 boys and 3 girls). The comparison group was composed of a GAP group of 15 adolescents ( 11 boys and 4 girls) belonging to another school from the same locality. The neighborhoods in which both secondary schools are situated are low middle class, and both schools are very similar in terms of size, quality of sports facilities and number of teachers. The physical education teacher of the intervention group was a male 30 years of age and held an undergraduate degree in Physical Education and a doctorate in Psychology. The physical education teacher of the comparison group was a male 35 years of age and held an undergraduate degree in Physical Education. Physical education activities conducted in their classes pertained to the official programme set by the Conselleria de Educación for the corresponding scholar level of the participants.

\section{Instruments}

The Multidimensional Scales of Perceived Self-Efficacy (MSPSE; Bandura, 1990, 2001)

We used four Children's Self-efficacy Scales, which were related to the subject of our research, as reported by Anderson, Sabatelli, and Trachtenberg (2007): Enlisting Social Resources (4 items; i.e., How well can you get teachers to help me when I get stuck on schoolwork), SelfRegulated Learning (11 items; i.e., How well can you finish my homework assignments by deadlines), Self-Regulatory Efficacy ( 9 items; i.e., How well can you resist peer pressure to do things in school that can get me into trouble.), and Social Self-Efficacy (4 items; i.e., How well can you make and keep friends of the opposite sex ). Responses were classified according to a 7-point Likert-type scale, anchored by not well at all (1) and very well (7). Cronbach' coefficient alpha for the subscales ranged from .63 for enlisting social resources to .86 for self-regulated learning (Choi, Fuqua, \& Griffin, 2001), and replicated those reported in Miller, Coombs, and Fuqua (1999). We used the MSPSE revised by Bandura (2001) and translated into Spanish by Olaz, Silva, and Pérez (2002). The coefficient alphas detected can be seen in Table 1.

Interviews were conducted by the authors of this manuscript in June in the school where the intervention had taken place with 15 participants of the intervention group (GAPgroup) and five GAP teachers (3 women and 2 men). The teachers were selected because they knew the participants of the intervention group very well, as they had been their teachers in previous years. The participants of the intervention group were asked the following

Table 1

Reliability alphas for the four self-efficacy dimensions of the Children's Self-Efficacy Scale at the three time points measured

\begin{tabular}{lccc}
\hline Source & Time 1 & Time 2 & Time 3 \\
\hline Self-efficacy for enlisting social resources & .65 & .86 & .69 \\
Self-efficacy for self-regulated learning & .85 & .90 & .90 \\
Self-regulatory efficacy for resisting peer pressure & .90 & .89 & .93 \\
Social self-efficacy & .82 & .79 & .82 \\
\hline
\end{tabular}

Note. 1: pre-intervention, 2: post-intervention, 3: follow-up 
questions: How would you assess your participation in the TPSR program?; Do you believe that your behavior has improved and that you have achieved some of the aims of the TPSR program? What have you learned in the TPSR program?; Have you applied what you have learned in the TPSR program in other areas, such as at home or in other classes? Have your parents or other teachers noticed changes after participating in the TPSR program? The three teachers interviewed were asked the following question: If you were to assess the TPSR program, what learning and changes have you observed among the students? We used pseudonyms to protect participant identity.

\section{Procedure}

Goals of the program: In this implementation of the TPSR model, the students learned responsibility progressively, moving through the following levels. Level 1 represents respect for the rights and feelings of others. Level 2 is participation and effort. Level 3 represents selfdirection, with an emphasis on the adolescents learning to be responsible and managing their time. The objective of level 4 (helping and leadership) is to educate the students so that they acquire a sense of moral commitment, defining morality to be the capacity to consider the well-being of others. Finally, level 5 (outside the gym) consists of the application of what has been learned in the program to other contexts.

Teacher's Responsibility: (a) To develop caring relationships and focus on strengths and positive behaviors, (b) To provide the students with opportunities to make informed decisions and to give back to their communities, (c) To integrate the teaching of responsibility into the physical education curriculum, (d) To foster empowerment, (e) To talk about transfer.

Daily structure of each session of the program. (a) Educational goal of the session: Every day, upon arrival at the gym, during the first five minutes, the personal and social responsibility behaviors to be practiced that day were explained, in order to make the expectations of the class clear. The session's goal was always related to one of the levels, with which the students were familiar and which were posted on the walls of the gym. We worked progressively from level 1 up to level 5; (b) Sport activity or game: Next, the day's sport activity and its rules were explained. The aim of the activity was for the students to both practice responsibility and learn to behave according to the day's goals. The session lasted 20 minutes; (c) Group meeting: The adolescents sat together in a circle with the program leaders. The students were given the floor so that they could share opinions, feelings and ideas about the program in general and the session in particular. The meeting lasted about 10 minutes; (d) Evaluation and self-evaluation: Still seated in a circle, the daily session concluded with an evaluation by each youth of his/her own behavior in class in relation to the level being worked on that day, and of their peers and instructors. They used a thumb gesture (up, horizontal or down) to give a positive, neutral or negative evaluation. This exercise lasted two to three minutes.

Physical Activities. The sport and physical activities were designed according to the educational goals of the responsibility levels. We sought to provide a variety of activities and ensured that the level of difficulty did not exceed the capacities of any of the students, so that they all had a chance to experience success. The activities can be seen in Table 2.

\section{Implementation of the Program}

The principal and teachers from the school to which the intervention group belonged were contacted in order to explain the program to them and to request their participation. The project was well received by all the teachers of the GAP group. The physical education teacher, who was responsible for carrying out the intervention, demonstrated great interest in participating in the project and in being trained to apply the program. Permission of the pupils' parents was secured before initiating the program. The intervention was carried out between November and May of the school year, during physical education classes, which took place twice a week, each class lasting an hour and a half.

Training of the physical education teacher. In the month of September, before the school year initiated, the first three authors of this report trained in a course of 30 hours, to train physical education teacher of the intervention group. The course consisted of 3 modules: (a) Theoretical basis of the personal and social responsibility model, (b) Previous application of the personal and social responsibility model, (c) Strategies for implementing the personal and social responsibility model in physical education classes. The teacher was provided with reading material and a manual of the program (Escartí, Pascual, \& Gutiérrez, 2005). The teacher in charge met the researchers every fifteen days to analyze the sessions of the program and to progressively incorporate the levels of responsibility and the educational goals in accordance with the students' progress.

Training of the classroom teachers of the intervention group. Had the objective that the classroom teachers backed implementation of the TPSR conducted in the Physical Education class. The researchers taught the basics of the TPSR model to the classroom teachers of the intervention group ( 3 females and 2 males, with an average age of 35 years) during a 6 hour training session.

Training of the intervention group students: At the beginning of the program the physical education teacher dedicated 6 hours of class to familiarising the students with each level of responsibility. The teacher divided the 15 students into groups of 5 and requested each group to write the meaning that each level had for them and to give specific examples of behavior related with the levels of 


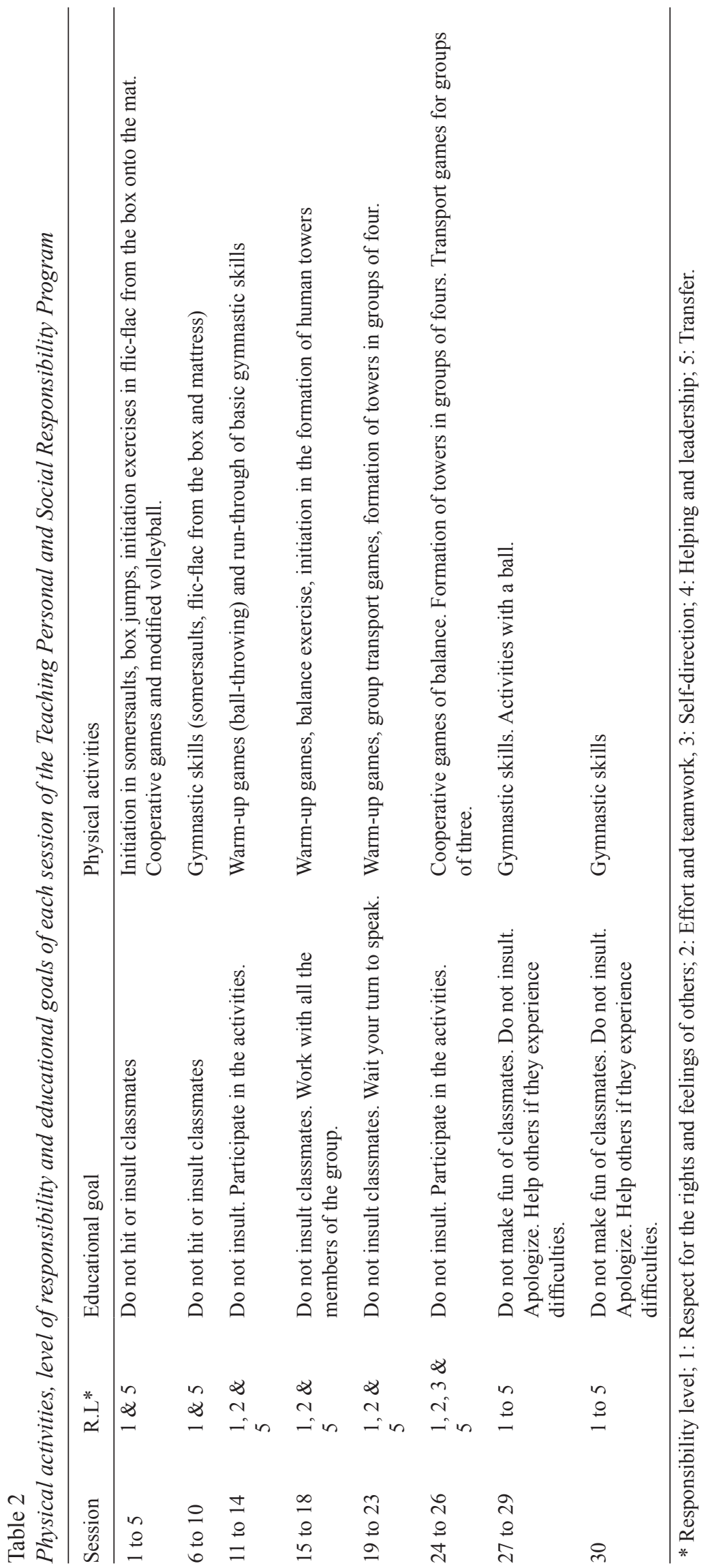


responsibility. Finally, after a discussion, the total group set out a series of educational goals for each level of responsibility (see table 2).

\section{Data Collection}

Program evaluation interviews (Patton, 2002) were the primary source of data when the program finished in June.

The Multidimensional Scales of Perceived Self-Efficacy (MSPSE; Bandura, 1990, 2001). were given individually to each of the participants (both intervention and comparison groups) in the classroom in October, prior to the beginning of the program, when the program ended in June, and six months later (in December).

\section{Data analyses}

Two sets of analysis were conducted. The first analysis examined participants' retrospective reports of their experiences during the program intervention. The questions were included in the post-test survey by means of a standardized open-ended interview (Patton, 1990), which was administered to the subjects of the intervention group and the three teachers. The second set of analyses were 2 (Group) x 3 (Time) factorial analyses of variance with Repeated Measures in the second factor. The Group factor (independent variable) included both intervention and comparison groups. The Time factor included three time points: before intervention, after intervention, and followup at six months. Given that the independent variable Time is a repeated measures factor, the sphericity assumption was tested and the Huyhn and Feldt correction was applied where necessary (Stevens, 1999). The dependent variables were the four self-efficacy factors. All the analyses of variance were performed in SPSS 15. Eta squared $\left(\eta^{2}\right)$, a measurement of size effect, was calculated for each effect in the design. The measurement of effect size is particularly relevant in this case given the small sample size. Cohen (1977) characterizes the effect size as small $\left(\eta^{2}=.01\right)$, medium $\left(\eta^{2}=.06\right)$ and large $\left(\eta^{2}=.13\right)$.

\section{Results}

Results of the student interviews: Once the transcriptions of all the interviews had been completed we performed an "individual case study" for each student. The descriptive analysis was carried out by the report's third and fourth authors. We performed a "cross case analysis" (Patton, 1990) of the differences and coincidences of the responses of the participants through a continuous comparison. To finalize, we grouped the information analyzed into three topics: (a) assessment of the experience, (b) learning and changes, (c) transference.
1) The experience was considered positive by all the students participating in the program. The principal motives that led them to this evaluation were the improvement noted in the Classmates' behavior the qualities of the physical education teacher, the good relationship they had with him, and the physical activities (generally considered attractive), that they performed in class. For example:

"I think that I have learned to behave better towards others, when there was a fight, speaking with whoever was annoying me,..." (Interview with David 4/6/2007, p. 1)

2) The students attributed changes that they noticed in their classmates to the PRPS. According to the data obtained we have classified these as: changes observed in themselves, changes observed in others, and lastly, changes in themselves observed by others. Each and every one of the students emphasized that there had been an improvement in terms of self-control in situations of conflict and respect for others. All of them pointed out that, as a result of the program, they now used dialogue to resolve problems with their classmates. Below, we include an example of a comment made by one student referring to the use of dialogue for the resolution of conflicts:

"I think I have learned to behave better towards others, to control myself, to not start the activity without the rest... whenever there is a fight to always talk to them, to whoever is annoying me, and..." (Interview with Rubén 4/6/2007, p. 1)

On the other hand, the following quote clearly demonstrates the improvements related to self-control and respect for classmates:

"I think that I have learned to behave better towards my classmates, because before, when they did something to me, even if it were (sic)a joke, I always got angry and insulted them" (Interview with José Manuel 3/6/2007, p.2)

Two of the students spoke of other changes that we summarize as following: improvements with respect to the rules, respect for people's turn to speak, a greater willingness to enter into dialogue with classmates and parents, not to cheat in the games, cooperation and team work, participation in the activities proposed in class (both the physical exercises and discussion part/reflections at the end of the classes) and recognition when they did something bad (self-criticism).

In the following paragraphs we offer examples that reflect the perceptions of these students about some of the abovementioned aspects.

With regard to the more pro-diaolgue attitude towards classmates and parents, David says that he has learned: "to talk more to my classmates and my parents and to get on better with them too" (Interview with David 4/6/2007, p. 2).

In relation to improvements in self-criticism Rubén states: ... "Well... if the class hasn't gone well, you know, to say so and the next time you can have more...you can do it better so that it doesn't happen again." (Interview with Rubén 3/6/2002,p.2) 
In addition, David continues to refer to this subject by stressing that he is now capable of recognizing that he has committed a mistake during the game and to apologize for it.

"Well..., because now, whenever I am fouled, I say that they

have fouled me, and if I do the same I say sorry, I apologize"

(Interview with David 4/6/2007, p. 2).

In terms of the changes observed in others by the students interviewed, the majority felt that an improvement had occurred in all the classmates that had participated in the program with respect to self-control and respect towards others. For example, Daniel affirmed: "they have improved, at the beginning they were always fighting, but not any more, they don't insult each other or hit each other" (Interview with Daniel 4/6/2007, p.1).

Rubén agrees that he has noticed changes in all his classmates: "all of us have changed, because before they called you "idiot" and now they don't say it to you or before they called you "idiot" and you said it back to them...and now nobody says it to you...or if they say it to you you don't (sic) say anything back to them, and so, you just ignore them and that's it" (Interview with Rubén 3/6/2007, p. 3).

Nevertheless, David, one of the students interviewed declares that some of the members of the class have improved in their behavior while others have not, though he considers that he has noticed changes in the majority (Interview with David 4/6/2007, p. 4). On the other hand, José Manuel, another classmate interviewed, after affirming that an improvement has occurred in the behavior of all his classmates, and in the use of dialogue to solve problems, comments "Those that never pay attention, the ones that are always messing around, they should be disciplined, because it's always the same ones, they are always talking" (Interview with José Manuel 3/6/2007, p.3).

With respect to changes in the students observed by others, all those interviewed declared that parents, or some teachers, or both had made some comment about the improvement in their behavior. The following quotes from the students reflect this:

"Yeah, a teacher, she told me that I study beter and that I do better exams and everything, and that my attitude to doing homework has changed (sic)" (Interview with Rubén 3/6/2007, p.4).

"Well, they tell me that I have changed, that I have improved, that I behave better than before" (Interview with Daniel 4/6/2007, p.3).

3) Regarding the transfer of learning, all students affirmed that they do not apply the improvements in certain behaviors only to physical education classes but that they also put them to practice in the playground, in the street and at home. Examples:

"You know...if they say to you on the street...that...you're on a bike for example, and they're playing football... well you don't cycle through them but go round them so that you don't disturb them, your classmates"
"Now I don't do the same as before, now I go to the library, I do my homework, and then I go home and if my gran needs something I go and I buy her whatever she needs". (Interview with Tania, 3/6/2007 p.2, 32-34).

"lots of times at home I interrupted my mum; but now I speak when she has finished speaking”. (Interview with Víctor, 3/6/2007 p.2, 13-14).

Results of the interviews with the teachers:

The teachers who were interviewed had an in-depth knowledge of their students, as they had been teaching them for several years.

1) Evaluation of the program, all the teachers interviewed positively evaluated the TPSR as a method for at-risk adolescents to learn behaviors of responsibility, highlighting the utility of the program's method. Examples:

"I have full faith in what can be achieved with the methodology that has been used in the TPSR program..." (Interview with Javier, 7/6/2007 p.1, 16-19).

"I think it is a very interesting and appropriate program for use inside and outside school with children and adolescents at risk. It is very organized and follows levels that make the work of the instructor easier and favours comprehension among the students"... "In terms of positive aspects I would highlight the importance of working on personal and social responsibility in order to train citizens and people, given that the work with attitudes favours the development of the child and his/her adequate socialization". (Interview with Luisa, 7/6/2007 p.1, 5-8 y 10-12).

2) Learning and changes observed. The most obvious has been the improvement in the behavior of the students in class, with a greater willingness to listen and a greater capacity to use dialogue to negotiate conflicts. The participants displayed very disruptive behavior at the beginning of the school year and a very positive evolution was observed over the course of the year, with an improvement in said behavior and the incorporation of attitudes and behaviors of responsibility that were not evident at the beginning of the program. Examples:

"They have improved in responsibility, with all that it implies: respecting others, helping them, doing things autonomously, participating and making an effort and applying what has been learned". (Interview with Esther, 7/6/2007 p.1, 43-45).

"Conducts that were not evident at the initiation of the program were evident at the end without the need for reminding them, and negative conducts have disappeared in the majority of cases". (Interview with Diana, 7/6/2007 p.1, 36-41).

\section{Quantitative Results}

A 2 (group) x 3 (time) analyses of variance with repeated measures in the last factor was conducted to assess main and interaction effects on self-efficacy of 


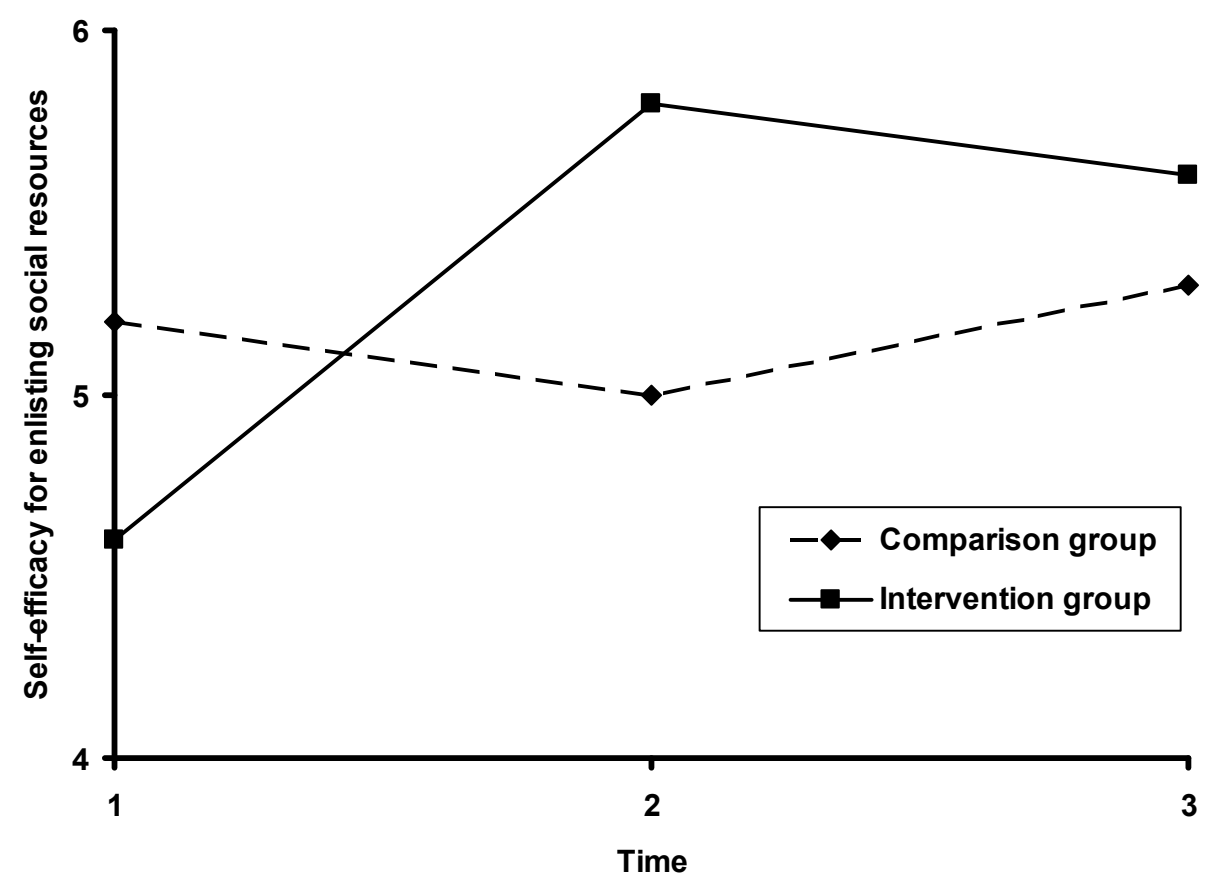

Figure 1. Estimated marginal means of self-efficacy for enlisting social resources.

enlisting social resources. Main effects of group and time were not statistically significant: $F(1,28)=.631$, $p=.434$, and $F(2,56)=2.685, p=.077$ respectively, while interaction was statistically significant: $F(2,56)=4.260$, $p=.019$. The interaction shows that the intervention had a significant effect (see Figure 1), since the intervention group's self efficacy changed from being worse than that of the comparison group prior to the intervention to surpassing it following intervention. The improvement produced by the intervention was maintained during follow-up. The comparison group, on the other hand, presented similar levels of self-efficacy at different temporal points, thus showing no significant improvement in that area.

In the case of self-efficacy for self-regulated learning, neither the main effect noted for Group, $F(1,28)=.664$, $p=.422$, nor the Time factor, $F(2,56)=1.748, p=.183$, was statistically significant. The interaction of Time $\mathrm{x}$ Group was statistically significant, $F(2,56)=3.759, p=$ .029 , which demonstrates that the intervention produced an important effect, with a value of $\eta^{2}=.118$. The intervention group began at a lower level than the comparison group but, following intervention, the former scored higher than the latter and remained at that newly acquired level (see Figure 2).

The main effect for Group was not statistically significant for self-regulatory efficacy to resist peer pressure, $F(1,28)=$ $1.685, p=.205$, but the main effect for Time was significant, $F(2,56)=8.475, p=.001$. The interaction Time $\mathrm{x}$ Group was not statistically significant, $F(2,56)=2.013, p=.149$. Since both groups improved their ratings between the first and second time, the effect achieved cannot be attributed solely to the intervention, although it is significant that the intervention group's progress mirrors that of the comparison group, especially considering that they began the program with lower scores.

Finally, with respect to perceived social self-efficacy, we found statistically significant results for the factor Time, $F(2,56)=8.717, p=.001$, which showed an elevated effect size, $\eta^{2}=.237$. On the other hand, the main effect for Group was not significant, $F(1,28)=2.152, p=.154$ and neither was the interaction of Time $\mathrm{x}$ Group, $F(2,56)=.319, p=$ .705 , as both groups improved over time, which cannot be attributed solely to the intervention.

\section{Discussion}

With respect to the first question that this research aimed to tackle, the appraisal of the teachers seems to confirm that the responsibility behavior of the participants improved during the course of the implementation of the TPSR. The teachers attributed the improvements of the youngsters in the intervention group to the program, and in particular evaluated their own participation in the the TPSR, though indirect, as a positive experience that has helped them to improve as teachers. Regarding the second question that we wished to explore, we can affirm that the students' evaluation 
of their participation was very positive. They perceived that the program helped them to improve their responsibility behaviors both in school and in other contexts. In the same way, they evaluated their participation in the program as a gratifying experience. The evaluation of those involved in the program is important because it determines the level of satisfaction that the program provides and is another indicator of its effects and its quality.

The results of our intervention indicate that the TPSR program, when applied to adolescents during the course of a school year, can produce an improvement of self-efficacy for enlisting social resources and self-efficacy for selfregulated learning. Based on what we have observed, in the process of learning personal and social responsibility, adolescents develop more positive beliefs regarding their ability to manage social resources, thereby improving their perception of their capacity for self-control and for resisting peer pressure. In other words, the model's teaching method, when employed to teach personal and social responsibility, enhances the self-efficacy beliefs of participants, consequently bolstering the adolescent's structure of the self in a vital way and increasing his/her sense of life satisfaction, as stated by Pajares (2006) and Vecchio, Gerbino, Pastorelli, Del Bove, and Caprara (2007). We believe that the process of reflection that formed an intrinsic part of the program, together with the positive feedback transmitted by the participants during each session, promoted the development of self-efficacy beliefs in the areas evaluated. This style of intervention is based on the Self-Efficacy Theory, which places great emphasis on the way in which individuals acquire self-efficacy beliefs (Bandura, 1977). Our study included a comparison group in order to provide additional evidence that all of the changes noted were directly related to the intervention rather than to non-specific factors such as involvement in a group process. Furthermore, the follow-up data would suggest that the results obtained have long-term effects.

In our educational program, we incorporated the model as you have before (Hellison, 1995) into the physical education curriculum. Using this model, we have attempted to put into practice a method of communication between the teacher and the students. The levels of responsibility proposed by Hellison (1995) proved to be excellent markers of appropriate behavior among students. Furthermore, in our study, there was a starting point at which the students learned to self-impose limits on their behavior and to reflect on their capacities. Participants felt capable of accomplishing the goals established at onset with or without success. The philosophy of this program is based on transferring the responsibility of the teacher to the students, so that the youths assume challenges when faced with difficulties and become more aware of their strengths and self-efficacy than of their weaknesses (Hellison, 2003; Martinek \& Ruiz, 2005; Martinek, Shilling, \& Johnson, 2001; Walls, 2007).
The methodological shortcomings of this study should be contemplated when taking into account its results. In the first place, the low number of particpants is a limitation. Future studies with larger samples of at-risk adolescents are necessary. Secondly, we consider that, in future research, participants' gains in personal and social responsibility should also be measured. Our study did not assess this due to the lack of an objective measurement that would have provided us with such data. In this way, we believe that future research should incorporate some of the scales recently created based on the Hellison model (1995) in order to measure personal and social responsibility (i.e. the Contextual Self-Responsibility Questionnaire, by Watson, Newman, \& Kim, 2003; Personal and Social Responsibility Questionnaire-PSRQ, by Li, Wright, Rukavina, \& Pickering, 2008).

In conclusion, our work has important implications for future research, as it endorses the TPSR program as an effective methodology for improving fundamental areas of psychological and social development in at-risk adolescents. Moreover, it supports physical education classes as an important arena for working with said subjects. Further research is necessary and should both involve a larger number of adolescents and explore, through longitudinal studies and multiple methodologies, the long-term effects of the TPSR program on adolescent participants.

\section{References}

Anderson, S. A., Sabatelli, R. M., \& Trachtenberg, J. (2007). Community police and youth programs as a context for positive youth development. Police Quarterly, 10, 23-40.

Bandura, A. (1977). Self-efficacy: Towards a unifying theory of behavioral change. Psychological Review, 84, 191-215.

Bandura, A. (1990). Multidimensional Scales of Perceived SelfEfficacy. Stanford, CA: Stanford University.

Bandura, A. (1997). Self-efficacy: The exercise of control. New York: Freeman.

Bandura, A. (2001). Guide for Constructing Self-efficacy Scales (Revised). (Unpublished manuscript). Available from Albert Bandura, Stanford University.

Brustad, R., \& Parker, M. (2005). Enhancing positive youth development through sport and physical activity. Psychologica, 39, 75-93.

Caprara, G. V., Barbaranelli, C., Pastorelli, C., \& Cervone, D. (2004). The contribution of self-efficacy beliefs to psychosocial outcomes in adolescence: Predicting beyond global dispositional tendencies. Personality and Individual Differences, 37, 751-763.

Catalano, R. F., Arthur, M. W., Hawkins, J. D., Berglund, L., \& Olson, J. J. (1998). Comprehensive community- and schoolbased interventions to prevent antisocial behavior. In $\mathrm{R}$. Loeber, \& D. P. Farrington (Eds.), Serious and violent juvenile offenders: Risk factors and successful interventions (pp. 248283). Thousand Oaks, CA: Sage. 
Cecchini, J. A., Montero, J., Alonso, A., Izquierdo, M., \& Contreras, O. (2007). Effects of personal and social responsibility on fair play in sports and self-control in school-aged youths. European Journal of Sport Science, 7, 203-211.

Choi, N., Fuqua, D. R., \& Griffin, B. W. (2001). Exploratory analysis of the structure of scores from the multidimensional scales of perceived self-efficacy. Educational and Psychological Measurement, 61, 475-489.

Cohen, J. (1977). Statistical power analysis in the social sciences. New York: Academic Press.

Collingwood, T. R. (1997). Providing physical fitness programs to at-risk youth. Quest, 49, 67-84.

Collingwood, T. (1996). Helping at-risk youth through physical fitness programming. Champaign, IL: Human Kinetics.

Cutforth, N., \& Puckett, K. (1999). An investigation into the organization, challenges, and impact of an urban apprentice teacher program. Urban Review, 31, 153-172.

Danish, S. J., Forneris, T., \& Wallace, I. (2005). Sport-based life skills programming in the schools. Journal of Applied School Psychology, 21, 41-62.

DeBusk, M., \& Hellison, D. (1989). Implementing a physical education self-responsibility model for delinquency-prone youth. Journal of Teaching in Physical Education, 8, 104109.

Escartí, A., Gutiérrez, M., Pascual, C., Marín, D., MartínezTaboada, C., \& Chacón, Y. (2006). Enseñando responsabilidad personal y social a un grupo de adolescentes de riesgo: Un estudio observacional. Revista de Educación, 341, 373-396.

Escartí, A., Pascual, C., \& Gutiérrez, M. (2005). Responsabilidad personal y social a través de la educación física y el deporte. Barcelona: Graó.

Hellison, D. (1985). Goals and strategies for physical education. Champaign, IL: Human Kinetics.

Hellison, D. (1995). Teaching responsibility through physical activity. Champaign, IL: Human Kinetics.

Hellison, D. (2003). Teaching responsibility through physical activity (2nd ed.). Champaign, IL: Human Kinetics.

Hellison, D., \& Walsh, D. (2002). Responsibility-based youth programs evaluation: Investigating the investigations. Quest, 54, 292-307.

Hellison, D., \& Wright, P. (2003). Retention in an urban extended day program. Journal of Teaching in Physical Education, 22, 369-381.

Herr, E. (1989). Counseling in a dynamic society: opportunities and challenges. Alexandria, VA: American Association for Counseling and Development.

Li, W., Wright, P., Rukavina, P. B., \& Pickering, M. (2008). Measuring students' perceptions of personal and social responsibility and the relationship to intrinsic motivation in urban physical education. Journal of Teaching in Physical Education, 27, 167-178.

Martinek, T., \& Ruiz, L. M. (2005). Promoting positive youth development through a values-based sport program. International Journal of Sport Science, 1, 1-13.
Martinek, T., Shilling, T., \& Johnson, D. (2001). Transferring personal and social responsibility of underserved youth to the classroom. The Urban Review, 33, 29-45.

Miller, J. W., Coombs, W. T., \& Fuqua, D. R. (1999). An examination of psychometric properties of Bandura's Multidimensional Scales of Perceived Self-Efficacy. Measurement and Evaluation in Counseling and Development, 31, 186-196.

Olaz, F., Silva, M. I., \& Pérez, E. (2002). Guía para la construcción de escalas de autoeficacia. [Guide for Constructing SelfEfficacy Scales]. Evaluar, 2, 1-37.

Pajares, F. (2006). Self-efficacy during childhood and adolescence: Implications for teachers and parents. In F. Pajares, \& T. Urdan (Eds.), Self-efficacy beliefs of adolescence (pp. 339367). Greenwich, CT: Information Age Publishing.

Patton, M. Q. (1990). Qualitative evaluation and research methods. Newbury Park, CA: Sage.

Patton, M. Q. (2002). Qualitative research and evaluation methods. Newbury Park, CA: Sage Publications.

Petitpas, A. J., Cornelius, A. E., Van Raalte, J. L., \& Jones, T. (2005). A framework for planning youth sport programs that foster psychosocial development. The Sport Psychologist, 19, 63-80.

Sandford, R. A., Armour, K. M., \& Warmington, P. C. (2006). Re-engaging disaffected youth through ohysical activity programmes. British Educational Research Journal, 32, 251271.

Siedentop, D. (1994). Sport education: Quality PE through positive sport experiences. Champaign, IL: Human Kinetics.

Steinberg, L. (1993). Adolescence. New York: McGraw-Hill.

Stevens, J. (1999). Intermediate statistics: A modern approach. Mahwah, NJ: Lawrence Erlbaum Associates.

Vecchio, G. M., Gerbino, M., Pastorelli, C., Del Bove, G., \& Caprara, G. V. (2007). Multi-faceted self-efficacy beliefs as predictors of life satisfaction in late adolescence. Personality and Individual Differences, 43, 1807-1818.

Walsh, D. (2007). Supporting youth development outcomes: An evaluation of a Responsibility Model-Based Program. The Physical Educator, 64, 48-56.

Watson, D. L., Newton, M., \& Kim, M. S. (2003). Recognition of values-based constructs in a summer physical activity program. Urban Review, 35, 217-232.

Weissberg, R. P., Kumpfer, K. L., \& Seligman, M. E. (2003). Prevention for children and youth that works: An introduction. American Psychologist, 58, 425-432.

Wright, P. M., \& Burton, S. (2008). Implementation and outcomes of a responsibility-based physical activity program integrated into an intact high school physical education class. Journal of Teaching in Physical Education, 27, 138-154.

Received March 15, 2009 Revision received September 10, 2009 Accepted November 21, 2009 
Reproduced with permission of the copyright owner. Further reproduction prohibited without permission. 